\title{
Exploring the Facts and Fantasies in Neal Town Stephenson's 'The Diamond Age: Or a Young Lady's Illustrated Primer'
}

\author{
Jushaini.P \\ Assistant Professor in English \\ Perinthalmanna, Kerala, India \\ jushainiashraf@gmail.com
}

\begin{abstract}
Literature enables people to think out of the box and connect with new ideas. At the same time, it takes us back and helps us know more about the life led by our ancestors. As a great foundation of life, literature fosters the overall development of the people and the society through inspiring stories, motivating tales and futuristic writings. We live in a world of technological advancements and Science Fiction stories are the profound ways to introduce extrapolation and speculation in literature. Built on a strong foundation of realistic concepts, sci-fi stories develop a futuristic world of limitless possibilities. Sci-fi stories take us to an exciting world where one witness unimaginable applications of science and technologies.

Neal Town Stephenson is an American writer well-known for writing science fiction, cyberpunk and postcyberpunk stories. He belongs to a prestigious family of scientists and engineers. His father was a biochemistry professor and his paternal grandfather, a physics professor. After completing his studies from Boston University, he started working as an advisor for Blue Origin, a company specialized in developing spacecraft and space launch systems.
\end{abstract}


Currently, he is serving as the chief futurist for Magic Leap. He also cofounded Subutai Corporation, a company dedicated to developing interactive fiction projects.

The Diamond Age: Or, a Young Lady's Illustrated Primer is a postcyberpunk novel by Neal Town Stephenson. The novel's protagonist is named Nell, who is a thete, meaning a person who is not a member of any of the phyles. The entire plot is set in a future nanotech world where three forms of tribes or phyles exist, known as the Han, the Neo-Victorian New Atlantis, and the Nippon. The Diamond Age details some of the applications of nanotechnology such as chevaline, smart paper, etc. This journal is an analysis of extrapolation and speculation used in the sci-fi novel, The Diamond Age, written with an aim to explore different facts and fantasies created by the author.

Keywords: Nanotechnology, Nanotics, Chevaline, Smart Paper.

The Diamond Age: Or, a Young Lady's Illustrated Primer is a sci-fi story centered around a young girl named Nell. The four-year-old Nell is a thete, meaning a person who is not a member of any of the phyles. The entire plot of the novel is set in a post-nation-state world of the future, and the peculiarity of such a world is that it is dominated by the advances in nanotechnology. The concept of nations has been shattered in this world and people are classified into specific groups known as phyles based on their skills and affinity towards computer technologies.

The protagonist in the novel, Nell once receives a copy of an interactive book 'A Young Lady's Illustrated Primer: A propaedeutic enchiridion’ from her brother Harv. As both Harv and Nell belong to the lowest class in the society with no access to education, they live in the leased territories of the Diamondoid Island of new Chusan, Shanghai. John Hackworth, an 
expert nanotechnologist, was approached by Lord Alexander Chung-Sik Finkle-McGraw to develop an interactive book for his granddaughter Elizabeth Finkle-McGraw. Hackworth developed two copies of the book with an intention to give one copy to his younger daughter, Fiona. But Hackworth was mugged by Harv on his way home and the illicit copy came into the hands of Harv, which he had later given to Nell. A Chinese black market engineer with a strange character, Dr. X was the one who had contacted Harv to rob Hackworth to get a copy of the book for him. Here, Neal Stephenson imagines a world where the nations are dissolved to create a world where there are three different sovereign enclaves affiliated to a single metropolis.

A perfect blend of extrapolations and speculations, The Diamond Age: Or a Young Lady's Illustrated Primer inspires the readers in every possible way. The ideas used in the novel exhibit the creativity of the writer as well as his in-depth knowledge of nanotechnology and artificial intelligence. The book got published in the year 1995 and witnesses some of the brilliant experiments that came out to be realities in the later years. Let us discuss in detail about the real scientific technologies and facts used in the novel.

There are three real-life technologies which require a special mention here. They are smart paper, matter compiler, and mites. The book clearly acknowledges the contributions made by the well-known nanotechnologists like Feynman, Drexler, and Merkle. The interesting part of the book is that it amazingly explains human interactions with these technologies.

\section{Smart Paper}

Electronic paper or smart paper has an appearance similar to that of ordinary paper and has a thin film transistor display that reflects light instead of emitting the light. This e-paper uses plastic substrates for display and is very flexible to use. Even under direct sunlight, the images 
and texts appear to be visible and retain high clarity. Displaying personalized news headlines is an important attribute of smart papers. The display film consists of millions of mediatrons and a distributed network of computers is positioned in between these mediatrons. The reader can see the same in the novel, The Diamond Age: Or, a Young Lady's Illustrated Primer as: Smart Paper consisted of a network of infinitesimal computers sandwiched between mediatrons. $(P g: 64)$

These mediatrons or microcapsules consist of dark and light particles and carry opposite electric charges. These dark and light particles are subjected to give colour for the text. They are drawn to the surface of the sheet based on the direction of the electromagnetic field. Apart from this, the storage or memory space of smart paper is stated in Neal Stephenson's sci-fi story, 'The Diamond Age: or, a Young Lady's Illustrated Primer' as:

Like most cards, it was made of smart paper and had lots of memory space left over to store digitized information. $(\mathrm{Pg}: 228)$

\section{Matter Compiler}

The second concept is that of matter compilers. Matter Compiler or MC is a device designed on the basis of nanotechnology, where articles or products like water, food, blanket, etc. can be created based on a specific design. These articles can be created for free using Matter Compilers. Feeds serve as the raw material for Matter Compiler and the feed stream carries energy and basic molecules required to create basic articles. The source needed to produce feed stream is under the control of the Victorian phyle. An alternative to feed known as the seed is controlled by the Eastern phyle and has a decentralized method followed, unlike feed. 
In the real world, Matter Compiler is a novel framework that is required to design an arbitrary molecular structure based on a pick and place mechanism. The main function of a matter compiler is to correctly interpret the user-defined software instructions and to arrange atoms in a specified order to produce an article or a product.

Mites

One of the potential applications of nanotechnology is the development of Nano drones. In the sci-fi novel, The Diamond Age: Or, a Young Lady's Illustrated Primer, Neal Stephenson described a cool and smart technology known as Nano drones or mites. In the story, mites can do many extraordinary things. They can do street surveillance, make the sky microbe-free, work as an artificial immune system, enter into the human nervous system, etc. Nano drones possess incredible powers and have great applications in our society. Controlled by delicate sensors, nano drones can easily fit into your palms or even smaller than that. Some drones are designed to fly inside the houses and some are for street surveillance. These unmanned aerial vehicles also have serious applications in the medical and military sectors. Drones can be used in the diagnosis and treatment of various human diseases, deliver healing molecules to remove the fat inside the human arteries, military rescue operations, etc.

We can also see that there are concepts that are unrecognizable in many ways and are too far from reality. In between the fascinating adventures made by Nell and the execution of plans by John Hackworth to somehow regain the illicit copy of the book, 'A Young Lady's Illustrated Primer: A propaedeutic enchiridion', there comes an amazing line-up of fantasies that are disturbing and equally exciting. 
Neal Stephenson as a talented sci-fi writer had finely mixed extrapolations and speculations into the novel, The Diamond Age, which enables the readers to travel through various scientific and superficial moments. How the real world and the interaction with the book are explained in the book gives the readers an out of the world experience.

Here, we can see four main unrealistic concepts or mystified speculations - The Illustrated Primer, The Alchemist, Phyles and The Common Economic Protocol (CEP), which are contrary compared to the real world.

\section{Illustrated primer}

Undoubtedly, a great visualization of speculation in the form of an interactive electronic book is the illustrated primer. This book is developed by John Hackworth, an expert in nanotechnology and later falls into the hands of the young girl Nell. The book is a brilliant instrument that helped her to grow up to the expectations of the technology-centered world specified in the story. The book itself is a specially-designed computer called runcible and each page of the book is made of mediatron, which has a paper-thin display. The hardware of the computer is contained inside the spine of the book.

\section{Alchemist}

When the Lord Finkle-McGraw came to know that John Hackworth made two copies of the illustrated primer, he got expelled from the Neo-Victorian phyle. Dr. X, the black market engineer started blackmailing John Hackworth to build numerous copies of the book. Hackworth became gripped between the tortures of Dr. X and the Lord Finkle-McGraw. He was compelled to become a double agent and started searching for an elusive figure Alchemist in Vancouver. 
Phyles

In The Diamond Age: Or, a Young Lady's Illustrated Primer, Neal Stephenson completely squashes the concept of nations, instead, he created phyles. Phyles are the tribes' wherein people sharing a common culture, ethnic heritage, values, skills and affinity for computer technologies are grouped together. As in the modern world, where people are differentiated on the basis of the countries they are born, people in the futuristic world explained in the book are categorized under different sovereign enclaves controlled by a single metropolis. There are three types of phyles mentioned in the story, namely Han, the Neo-Victorian New Atlantis, and the Nippon. People who are not members of these three groups are known as Thetes. The protagonist of the story, Nell is a thete and comes from a deprived society. The phyle, Han consists of Han Chinese, the Neo-Victorian New Atlantis consists majority of Anglo-Saxons. They also accept people who share their same ideology, mainly Indians and Africans whereas; the Nippon phyle consists of Japanese people.

\section{Common Economic Protocol (CEP)}

All phyles specified in the novel are protected by a powerful system of justice known as Common Economic Protocol (CEP). The rules, regulations, and protocols designed under CEP are for exercising the peaceful existence of the people belonging to different phyles and to carry out healthy economic activity between these phyles. Somewhere similar to the real world organizations like United Nations (UN) and International Monetary Fund (IMF), Common 
Economic Protocol (CEP) upholds and supports the right to personal property and stringent laws are designed to punish people causing problems for the economic capability of other individuals.

The people who are not the members of any of these phyles or tribes are considered as second-class citizens by Common Economic Protocol (CEP). Many factors contribute to their second-class citizenship like economic conditions, no or less access to education, etc. The basic needs of thetes such as food, water, clothing, and shelter are made freely available to them under the strict instructions of CEP.

\section{Conclusion}

We can see an honest effort from the writer, Neal Stephenson to extrapolate from current events and speculate some incredible themes. The way three different storylines converge in the end drives readers into a fantasy world. In a nutshell, we can say that Neal Stephenson maintains ambivalence towards the consequence of futuristic technologies mentioned in the novel. 


\section{Works Cited}

Stephenson Neal. The Diamond Age: Or, a Young Lady's Illustrated Primer. Random House Publishing Group, 2003, p. 64.

Stephenson Neal. The Diamond Age: Or, a Young Lady's Illustrated Primer. Random House Publishing Group, 2003, p. 228.

Yedla, Suneetha. 'Smart Paper' in Neal Stephenson's 'The Diamond Age: Or, A Young Lady's Illustrated Primer'.” vol. 7, no. 3, Feb. 2013, pp. 51-53. IOSRJOURNALS www.iosrjournals.org/iosr-jhss/papers/Vol7-issue3/I0735153.pdf?id=5988.

Heth, Zachary. "The Diamond Age: Technology." CSI ASI EDU, Center for Science and the Imagination, 22 July 2014, www.csi.asu.edu/project-archive/optimism/the-diamond-agetechnology. 